\title{
London is an important barometer for the omicron wave in the United Kingdom
}

Twitter: @Azeem_Majeed Cite this as: BMJ 2022;376:042 http://dx.doi.org/10.1136/bmj.042

\section{Azeem Majeed professor of primary care and public health}

Over the last few weeks, the United Kingdom has experienced a record number of covid-19 infections, driven by the rapid spread of the omicron coronavirus variant, with the daily reported case numbers approaching 200000 on some days. ${ }^{1}$ This has placed considerable pressure on the NHS through a combination of people seriously ill from covid-19 and staff absences. ${ }^{2}$ Other parts of the economy, such as public transport, have also been badly affected by staff absences.

A sustained period of high infection rates would be very damaging for the UK. But there are now signs that the number of covid-19 cases in London-the first area of the UK to face the wave of infection from omicron-may have peaked. ${ }^{3}$ In which case, a similar pattern of declining case numbers may be seen in other parts of the UK later this month.

There were several factors that drove the early increase in omicron cases in London. London is the UK's main international travel hub with the UK's busiest airports located nearby. Overseas travellers who are infected with a new coronavirus variant are more likely to arrive in the London region than in other parts of the UK. London also has a very large number of international visitors-for activities such as work, study, tourism, leisure, and sports events. London is the UK's largest city and is very densely populated, with many overcrowded households, often with people from three or more generations living together, which makes infections more likely to spread, including to clinically vulnerable groups who will be at much greater risk of adverse outcomes such as hospital admission.

London also has a lower covid-19 vaccination uptake than other parts of the UK. Around $20 \%$ of people aged 12 and over in London remain unvaccinated, compared to a national average of about $10 \%$. Although vaccines provide less protection from symptomatic infection with omicron than from the previously dominant delta variant, they do still provide good protection from serious illness, particularly in people who have had their booster vaccination. The lower vaccination rate will lead to infections from omicron spreading more quickly in areas such as London; as well as increasing the likelihood of severe disease. This would in turn increase hospital admissions from covid-19 and pressures across the NHS in London.

After increasing very rapidly in London, the omicron wave now shows signs of abating with the number of covid-19 cases and hospital admission dropping in recent days. We can't confirm yet that the drop will continue; nor what the impact will be of schools, universities, and workplaces reopening. But if the decline is sustained, other parts of the UK can also expect to see similar falls later this month with case numbers dropping first, followed by a drop in hospital admissions after a lag period. This means that the outcome of the omicron wave well may be less severe than predicted in the more pessimistic government models, particularly in the areas of the UK with the highest vaccination rates. 4

However, we can't yet relax our covid-19 control measures. The number of covid-19 cases in the UK will remain high-compared to previous waves-for some time. The NHS will continue to be under pressure, perhaps for many months, trying to cope with the impact of covid-19 on top of the usual winter pressures that it faces each year, while also trying to deal with the backlog of work that has built up during the pandemic. The NHS will also continue to be affected by staff shortages due to illness. Although the government may wish to declare "victory" against omicron and end its Plan B measures later in January, it should refrain from doing so. The public also need to continue to practise good infection control measures, building on the "Three C Approach" to personal safety limit the impact of covid-19. ${ }^{5}$

Measures such as wearing face masks in indoor settings should remain in place, with the government and public health agencies encouraging people to use well fitting FFP2 masks that provide better protection for the wearer, rather than loosely fitting surgical or cloth masks. More targeted use also needs to be made of publicly-funded lateral-flow tests. ${ }^{6}$ Finally, the covid-19 vaccination drive must continue-for those who are currently unvaccinated as well as for those who are now eligible for a booster vaccine. A high uptake of booster vaccines will protect against serious illness and buy time until modified vaccines that target omicron become available later this year.

The experience of London offers some positive news for the rest of the UK and for the government. But we must remain cautious and continue with our covid-19 control measures until infection rates are substantially lower than they are now. We also need to be fully prepared to deliver another booster vaccination programme later this year, while also continuing to target the $10 \%$ of people aged 12 and over in the UK who remain unvaccinated.

Competing interests: I have read and understood the BMJ policy on declaration of interests. I have no competing interests.

Acknowledgments: AM is supported by the NIHR Applied Research Collaboration NW London. The views expressed are those of the author and not necessarily those of the NHS, the NIHR or the Department of Health and Social Care.

Provenance and peer review: not commissioned, not peer reviewed 


\section{OPINION}

1 The Guardian. UK Covid case numbers hit another record high at more than 189000 . December 2021. https://www.theguardian.com/world/2021/dec/30/uk-covid-case-numbers-hit-anotherrecord-high-at-more-than-189000

2 The Guardian. NHS trusts in England declare critical incidents amid Covid staff crisis. January 2022. https://www.theguardian.com/society/2022/jan/03/several-nhs-trusts-declare-critical-incidents-amid-covid-staff-crisis

3 GOV. UK Coronavirus in the UK. https://coronavirus.data.gov.uk/details/healthcare?areaType=nhsRegion\&areaName=London

4 The Guardian. When will Omicron peak in the UK and is the modelling wrong? January 2022 https://www.theguardian.com/world/2022/jan/03/when-will-omicron-peak-in-uk-and-is-themodelling-wrong

5 Majeed A. The Three C Approach to Personal Safety During the Covid-19 Pandemic. Imperial College London. December 2021. https://blogs.imperial.ac.uk/medical-centre/2021/12/15/thethree-c-approach-to-personal-safety-during-the-covid-19-pandemic/

6 Majeed A. It's time for more targeted use of lateral flow tests for covid-19 BMJ 2022; 376:028 doi: 10.1136/bmj.028 